\title{
Microsurgical treatment of tentorial dural fistulas causing thalamic venous hypertension: two illustrative sister cases
}

\author{
Gregory Glauser, BS, Tracy M. Flanders, MD, and Omar Choudhri, MD \\ Department of Neurosurgery, University of Pennsylvania, Philadelphia, Pennsylvania
}

This video is a presentation of technical tenets for the microsurgical clipping of a tentorial dural arteriovenous fistula presenting with thalamic venous hypertension. These cases are easily misdiagnosed and often supplied by the tentorial artery of Davidoff and Schecter. The cases shown in the video uniquely illustrate a supracerebellar infratentorial approach to identify and clip an arterialized tentorial vein utilizing intraoperative Doppler and fluorescein, with navigation and an intraoperative cerebral angiogram in a hybrid neuroangiography operative suite. Both patients were found to have thalamic edema on preoperative imaging, which significantly improved postoperatively.

The video can be found here: https://youtu.be/HmU06Ye53QI.

KEYWORDS dural arteriovenous fistula; venous hypertension; thalamic edema; cerebrovascular; video 